\title{
Workplace Injury and the Failing Academic Body: A Testimony of Pain
}

\author{
Helena Liu' ${ }^{1}$ \\ Received: 30 September 2020 / Accepted: 10 May 2021 / Published online: 19 May 2021 \\ (C) The Author(s), under exclusive licence to Springer Nature B.V. 2021
}

\begin{abstract}
This article explores how meanings around risk, health/safety, and workers' bodies are constructed in an academic context. I do so through the study of a single academic in Australia who sustained a back injury at work. Through an analysis of in-depth interviews and documents, I attempt to show the embodied experience of an injured worker's struggle for care, recovery, and survival in the neoliberal academy. Writing from the nexus of workplace health and safety and critical management literatures, the raw testimony of this injured academic lays bare the violences that are enabled within a wider culture of selfdiscipline, individualism, and performativity in the university. The story presented in this article exposes how physiological and psychological injuries can be exacerbated through the very health and safety procedures that are designed to prevent and alleviate harm. Please note that this article contains references to suicide and suicidal ideation.
\end{abstract}

Keywords Workplace injury $\cdot$ Occupational health and safety $\cdot$ Human resource management $\cdot$ Academia $\cdot$ Neoliberalism

\section{Introduction}

Work-related injury and illness, both physiological and psychological, have profound impacts on organisations including the cost of workers compensation insurance, replacement employment, lost working time and talent, as well as the indelible consequences on workers' bodies and lives (Fan et al., 2019; Ståhl et al., 2014). According to Takala et al.'s (2014, p. 326) study, there are 2.3 million deaths globally for reasons attributed to work each year. The primary cause of death are work-related diseases such as cancer, accounting for 2 million fatalities, while occupational injuries comprise the remaining 300,000 fatalities (Takala et al., 2014, p. 326). Non-fatal injuries tend to be under-reported, but have risen significantly in the last decade (Hämäläinen et al., 2017). The latest estimates from Hämäläinen et al. (2017, p. 11) suggest that there are 373 million work-related accidents around the world.

While industries such as manufacturing, construction, transport, and mining have received the most attention from OHS research given their prevalent risk of injury and illness, some emerging studies are also turning their attention to

Helena Liu

helena.liu@uts.edu.au

1 University of Technology Sydney, PO Box 123, Ultimo, NSW 2007, Australia contemporary forms of 'knowledge work'. Universities, in particular, have featured as sites of OHS interest, with concerns over the rising rates of work-related stress and mental illness (Morrish, 2019; Pignata et al., 2018; Winefield et al., 2008). Growing mental health risks in academia appear to coincide with the marketisation of universities under neoliberal capitalism (Ratle et al., 2020). A prevailing culture of 'targets and terror' (Jones et al., 2020) has institutionalised metrics-based management and exacerbated careerism, overwork, bullying, anxiety, and depression in academia (Clarke \& Knights, 2015; De Vita \& Case, 2016; Keashly \& Neuman, 2014; Smith \& Ulus, 2020).

Bringing these research interests in OHS and the neoliberal university together, the aim of this article is to explore the relational, organisational, ethical, and political dynamics of workplace injury from a critical constructionist lens. To achieve this aim, I investigate the following research questions:

(1) How is an incident of workplace injury constructed between the injured worker, their employer, and other social actors through the OHS process? (2) In what ways does power inform the construction of workrelated injury and its recovery?

In order to answer these questions, I conduct an empirical qualitative analysis of an academic who sustained a back injury at work in 2019. By focussing on an individual 
worker's case, I am able to explore the processes through which the injured academic attempted to navigate their recovery amidst complex, messy meanings around risk, health and safety, and the academic body as constructed between an injured worker, their organisation, and other social actors including health professionals, insurance managers, and state government advisors.

I follow the steps of critical scholars before me who commit to writing differently (Gilmore et al., 2019) and see writing as a form of resistance. In line with this tradition, I attempt to present the rich, qualitative data to which I have been granted in ways that centre the embodied individual, their physical and psychological suffering, and their fight for survival in academia (Smith \& Ulus, 2020). I hope this article contributes to ongoing critiques of the neoliberal university and extend existing knowledge by showing how individual, organisational, and sociopolitical dimensions of OHS interweave through a particular case of workplace injury and recovery.

\section{The Social Construction of Health and Safety}

Research of occupational health and safety (OHS) has grown and shifted in recent decades, expanding beyond the traditional medical focus on physical harm and its treatment, to broader understandings of safety that encompass both physiological and psychological health and wellbeing (Fan et al., 2019). Within organisations, OHS is one of the core responsibilities of human resources, yet despite these broader advancements in research and practice, management studies has been slower to develop research and theorising of OHS and its implications for workers and organisations (Fan et al., 2019).

Given the hegemonic status of neoliberalism in managerial theorising and practice, it is perhaps unsurprising that existing management research of OHS tends to concentrate on individual responsibility and compliance (Zoller, 2003). This individualistic approach has given rise to psychologistic treatments of OHS that are concerned primarily with individual employees' demographic attributes, risk perceptions, and safety attitudes and behaviours (Fan et al., 2019; Gifford \& Holmes, 1996; Laberge \& Ledoux, 2011; Shaw et al., 2003). Indeed, one of the earliest measures developed by the Tavistock Institute during the 1950s was of employees' 'accident proneness' (Miller \& Rose, 1988). Proponents such as Peter Castle (1956) hypothesised how workplace accidents were caused by worker's conscious and unconscious desires to withdraw from work.

Research of employees' perceptions of and responses to OHS policies, procedures, and practices has also been spurred by the influential work of Dov Zohar (1980) on safety climates. The safety climate literature has predominantly focussed on how employers may attempt to modify individual employees' perceptions on the value of safety at work in order to improve OHS measures (Hossain et al., 2015; Neal et al., 2000). In this way, the safety climate literature assumes greater responsibility for OHS on the part of the employer than more traditional approaches. For instance, this literature has promoted the importance of developing principled ethical climates in order to encourage safety-enhancing behaviours (Parboteeah \& Kapp, 2008). It has likewise been suggested that senior managers' safety behaviours may have a 'trickle down' effect and improve safety behaviours overall (Tucker et al., 2016). The subtext of many of these studies nevertheless see individual workers as the source of danger and risk and as the primary sites for change.

Research around psychosocial injuries is similarly inclined to focus on individual-directed interventions such as expanding employees' coping resources ('resilience' has become a popular construct as of late) and modifying their emotional appraisal of work-related stressors through training and development as well as employee assistance programs (Pignata et al., 2018). However, empirical studies of psychosocial health often conclude that the most effective interventions are multileveled, where individual-directed solutions are complemented with organisational strategies that address the work environment, technology, and job design (Richardson \& Rothstein, 2008; Saari, 1995).

Although psychological research of OHS has generated valuable and important insights, the overwhelming focus on individual factors means that critical and sociological concerns tend to be overlooked and remain less well understood overall (Zoller, 2003, 2009). Critical and sociological perspectives are not so much interested in identifying and enhancing safety attitudes of employees, but are more concerned with the co-constitution of OHS and its links with "the material and ideological circumstances of regulatory rules, managerial control, work processes, and social relationships" (Zoller, 2003, p. 119). The ideological, regulatory, managerial, organisational, and relational dimensions of OHS are important because examined together, they allow researchers to develop more holistic understandings of how workplace safety and hazards are socially constructed in organisations and informed by structures of power in the wider culture. The few critical voices in this space have shown that the dominant focus on individual factors has enabled organisations to downplay their workplace hazards and shift the responsibility for addressing and circumventing injury and illness onto employees (Fan et al., 2019; Frick, 2011; Hart, 2010). For instance, Gifford and Holmes' (1996) study of painters recounts how employers blamed individual painters' apathy as a personal failure to accept responsibility for risk control. Meanwhile, the owners of the painting 
companies attempted to reduce costs by purchasing cheap and poorly maintained equipment and stocking discounted, toxic chemicals.

This individuating trend has been part of a prevailing corporate social responsibility discourse that promotes the expectation that employers can and should self-regulate, as OHS is assumed to enhance organisational productivity, performance, and profit. However, relying on the business case in the argument for self-regulation is problematic as it neglects the important roles of strong, proactive legislation and worker involvement in OHS (Hart, 2010; MacEachen et al., 2016). The self-regulatory approach has also meant that employers rarely have the impetus to initiate structural remedies that lead to meaningful change (Hart, 2010), despite the dominant unitarist discourse that maintains what is good for workers is good for employers. The ethics of OHS is thus taken as given as OHS in and of itself is assumed to be exercised for both employees' wellbeing and organisational gain.

In some cases, studies have shown that organisations apply mechanisms to suppress worker reports of injury and disease (Frick, 2011). For instance, Zoller's (2003) study of an automobile manufacturing plant revealed how injured workers would be bandaged up on the job to discourage them from going to a clinic and having the injury recorded. When workers attempted to report work-related injuries and illnesses, they faced roadblocks from both management and physicians within the regulatory structures who challenged whether the claims were work-related (Frick, 2011; Zoller, 2003).

At the same time, newer forms of work that are associated with the private service sector (i.e. 'knowledge work') and changes to work made through increasing outsourcing, work intensification, and casualisation within the gig economy, generate new OHS risks that are not well accounted for in traditional OHS frameworks (Hart, 2010; MacEachen et al., 2016). In a context of growing precarity, workers face a dichotomy between health and work through what Zoller (2009) conceptualised as 'job blackmail'. The roots of this term can be traced to Kazis and Grossman (1991[1988], p. 7) who described how companies that produced environmental hazards blamed "faceless government bureaucrats and 'elitist' environmentalists" for plant closures and employee lay-offs. In Zoller's (2009) use of 'job blackmail', workers are similarly enlisted as sympathetic victims by organisations against a faceless enemy. Employers persuade them that the risks of injury and illness are essential to profitability, and therefore, assuming those risks is necessary to secure their employment. Without acknowledging the unequal power between capital and labour, explorations of OHS will struggle to develop a fuller picture of the challenges to creating safe work environments (Hart, 2010; MacEachen et al., 2016).
Considerations of how workplace injury and illness are managed is fundamentally about bodily integrity, which pertains to people's right to make decisions about what happens to their own body (Earp, 2015; Svenaeus, 2014). Though not without its share of backlash from the mainstream biomedical community, critical disability studies has brought considerations of bodily integrity to the forefront of bioethics (Garland-Thomson, 2017). Disabled scholar-activists have demonstrated the ways traditional biomedical scientific discourses construct disability as the failing of individual bodies, leading to ableist and at times even eugenist assertions about whether or not disabled bodies should be fixed or terminated (Newell, 2006). Disabled academics and activists advanced bodily integrity by defending their rights to embody their 'impairments' (Newell, 2006). These debates have implications for OHS, prompting considerations of how organisations exercise power in defining whose bodies are injured, ill, and impaired (or not) and how those bodies are to be managed.

Following critical constructionist scholars of OHS, I view the theorising and practice around workplace injury and illness as a discursive, political process. Where existing critical examinations have explored detailed cases of injuries at manufacturing plants (Zoller, 2003) and fatal accidents at offshore oil installations (Hart, 2013), here in this study, I explore the case of an academic who sustained a back injury in 2019 and her attempts to navigate the organisational and regulatory frameworks through her recovery. In conducting a qualitative study of a single individual, I am able to explore the interplay between an injured worker, their organisation, and other social actors such as health professionals, insurance companies, and state government advisors, in constructing an OHS incident and its recovery process. Before discussing the methods of data collection and analysis, I will provide an overview of the research context of higher education in order to contextualise the analysis of the experiences of an injured academic.

\section{Health and Safety in the Neoliberal University}

The site of this study is a university in Australia. To date, there have been few studies of workplace injury and illness in higher education, given the prevalence of more serious and fatal OHS risk within sectors such as manufacturing, mining, transport, and construction. Hossain et al. (2015) observe that among the limited studies of OHS in academic institutions, researchers tend to concentrate on safety procedures for working in laboratories, yet this near-exclusive concern with safe laboratories is rarely supported with more holistic managerial and operational considerations of the wider institution itself. 
However, a growing number of studies are exploring the psychosocial costs of university work such as stress (Kinman, 2001; Oketunji, 2014; Pignata et al., 2018; Watts \& Robertson, 2011), alongside declining academic work conditions under neoliberal capitalism (Connell, 2014; Giroux, 2014; Ratle et al., 2020). This line of inquiry has observed that university staff around the world are reporting growing work-related stress due to the increased casualisation and precarity of the workforce (Bone, 2020), external funding pressures, and competition (Pignata et al., 2018). In particular, widely reported suicides in universities in the past decade led to inquiries of the seeming 'epidemic of poor mental health' across universities in the United Kingdom (Morrish, 2019), with similar trends observed in United States, New Zealand, and Australia. Such reports have noted academics' health and wellbeing are impaired by increased job precarity, excessive workloads, growing class sizes, and punishing performance models monitored through excessive metrics and audits (De Vita \& Case, 2016; Morrish, 2019; Watts \& Robertson, 2011; Winefield et al., 2008).

These trends all occur within what critics have observed as the increasing neoliberalisation of academia. In this article, I take neoliberalism to be the complex, changing and at times contradictory set of practices organised around the universalisation of market-based social relations (Giroux, 2014; Manathunga and Bottrell 2019). Neoliberal academia is a discursive and performative space in which the ideal academic subject is formed as one who acts, speaks, thinks, produces and behaves in line with an economic rationale (Peruzzo, 2020). Disability comes into tension with a neoliberal system that marginalises and subjugates people whose bodies do not conform to its norms (Peruzzo, 2020). Disabled is thus traditionally an indictment of a body's reduced ability to produce capital.

The neoliberal, corporate university is in part enabled by the long-established patriarchal structures of academia (Manathunga and Bottrell 2019). Neoliberalism carried the prevailing masculinist ideals of rationality, individualism, and mastery into the 'new' university (Berg \& Seeber, 2016). For Smith and Ulus (2020), these gendered norms valorise competition and domination while offering little space for cooperation or care. Individuals resort to self-diagnosing, self-medicating, and self-disciplining their bodies in attempts to maximise their productivity while internalising any struggles to manage our work as personal failures (Peruzzo, 2020; Smith \& Ulus, 2020).

Research of ableism in academia has revealed the effects of this highly politicised system on disabled academics who bear the gamut of physical and mental disabilities, chronic illnesses, and neurodiversity. Disclosure often requires an intricate web of negotiations, wherein adjustments for absences from work or continued sick leave may frequently be questioned and denied (Brown, 2020). Whether or not academics choose to disclose their disabilities, they typically bear an added invisible and unpaid workload to participate on the same terms as an able-bodied peer (Brown, 2020). This labour creates an additional burden of 'passing' for disabled academics to compensate for the capital they are expected to generate, translated through the growing (in both volume and standards) performance indicators for research outputs, teaching loads, supervision, administrative duties, and more.

The forces of patriarchy and neoliberalism have shaped the changing nature of work (Connell, 2014). These changes were no more acute than during the COVID-19 pandemic when physical distancing guidelines rapidly transformed academic work, shifting almost all activities of research, writing, fieldwork, teaching, and meetings online. Measures to address the added risk of musculoskeletal injury through prolonged computer use were absent from many managerial directives to maintain the production of capital. Increased work pressures and demands have largely been left to individual staff to shoulder, supported with well-intentioned but trite calls to "do your best" (Utoft, 2020, p. 780).

In this article, I seek to connect the critiques of neoliberalism in academia with the in-depth analysis of organisational and individual dynamics through an OHS case of an injured academic. Her lived experiences reveal the ways sociopolitical and organisational dynamics interweave with the embodied individual in struggles over the meanings of risk, health and safety, and the academic body.

\section{Methods}

In 2019, I was contacted by an academic in Australia who had recently sustained a lower back injury. A mutual colleague had given her my contact details, believing I could offer advice about treatment and recovery as I had also survived a back injury the year before. Indeed, when I experienced my own injury, I was surprised by the number of colleagues who disclosed their own musculoskeletal issues, lending both information and support for my recovery. As their testimonies of pain emerged out of the woodwork, I appreciated then "the masculine structures and behaviours that are illustrative of neoliberal academia" (Smith \& Ulus, 2020 , p. 2). The prevalence of pain (both physical and psychological) that I experienced, along with a surprising number of my fellow colleagues, laid behind a façade of productivity, performance, and academic 'excellence'. After corresponding for a few months, the academic, who I will refer to under the pseudonym of Ashley, suggested that I interview her about her lived experiences with her injury. We debated about whether or not she could join me in a joint autoethnographic inquiry, but in the end, she decided she would prefer to remain anonymous. 
This study is positioned within a social constructionist paradigm that recognises the relational and contextual nature of social reality (Burr, 2003; see also Berger \& Luckmann, 1966). From a social constructionist approach, I see knowledge to be produced and reproduced through ongoing processes of meaning-making between social agents. As such, knowledges around risk, health and safety, and workers' bodies are not understood as having any fixed and universal 'objective' meanings (Turner \& Tennant, 2010). Rather, this study seeks to explore the explicit and implicit meanings around these constructs as they are negotiated within particular local contexts. For example, our participation in (often) mandatory OHS training produces collective understandings of organisational 'safety'. Individual safety checks like ergonomic self-assessments reinforce assumptions about who is responsible for everyday workplace safety and injury prevention. Social cues from colleagues, such as commonplace stories of sick or injured workers coming into work anyway, delivering classes with a fever, etc., communicate tacit expectations of workers and what they ought to be able to tolerate with regards to illness and injury. These everyday experiences of organisational life then inform our understandings of work and what it means to be a 'good' employee.

Power is central to the processes of social construction, informing which meanings produced (and reproduced) by whom will gain legitimacy. Critical constructionist research of OHS examines power through a sociological perspective that traces local meanings to prevailing ideologies such as patriarchy and neoliberalism (Hart, 2010; Zoller, 2003, 2009). Critical constructionist approaches demonstrate the importance of examining the mechanisms through which OHS is brought about in work and organisations and how those mechanisms are grounded in the historical, cultural, and socio-material contexts (MacEachen et al., 2016; Turner \& Tennant, 2010).

Ashley is an early career academic working as a marketing lecturer at an Australian university. She was in her early thirties at the time of her injury and identified as a cis-gender woman. I conducted a series of four formal interviews with Ashley over the span of five months between March and July 2020. The interviews totalled $7 \mathrm{~h}$ and $12 \mathrm{~min}$ and were all video recorded via Zoom. Although she had shared many details of her experiences informally with me prior to the interviews, they were opportunities to elaborate and codify the events of her injury and subsequent navigation through the organisational and regulatory frameworks. Given Ashley's understanding of research practice, our interviews were highly collaborative and unstructured. She organised the four interviews around the stages of her injury and recovery and I only interrupted her when I wanted to seek clarifying information and additional details about her account.
To supplement her account, Ashley sent me copies of all her documentation about her injury. I received a total of 24 files which included the original injury report, 12 workers compensation certificates, two letters from her General Practitioner (GP), one letter from her physiotherapist, and a return-to-work assessment from the rehabilitation manager. Ashley also shared with me six pages of notes from phone conversations with human resource staff from the time she first reported her injury.

Given the primacy of Ashley's account to the analysis, I need to emphasise that I am not presenting a realist representation of the events surrounding her injury. Were it possible to interview Ashley's manager, colleagues, healthcare professionals, and her institution's human resource staff, I would likely receive differing constructions about her injury and recovery process. Nevertheless, the focus here on Ashley's lived experiences is valuable as it has the potential to enrich the existing OHS literature by providing a vivid and detailed view from the perspective of an injured worker. It also supports the growing critical analysis of academia by showing how physiological and psychological harms may be exacerbated via university OHS procedures that are intended to reduce those harms.

In line with the critical constructionist approach to the study, the analytical process examined the struggles over meaning that Ashley recounted between herself, her organisation, healthcare professionals, and the insurer. Her notes and interpretations of the meanings asserted by other social actors were compared and written with direct quotes from the documentation. I paid attention to how neoliberal values informed the contradictory constructions advanced of Ashley's injury and recovery, revealing assumptions about the ideal academic body.

Transcripts and supplementary documents were coded through an iterative process driven by both theory and data. Coding began through a framework developed from the OHS literature that specified the causes, responsibilities, solutions, and triggers of the injury. Over time, the coding framework gradually expanded to incorporate recurring codes from the data, such as injury severity and scope, workplace adjustments, and suitable work duties. However, I decided to present the findings in a way that highlights Ashley's embodied and emotional testimony rather than my codified themes. Following recent trends in organisation studies rooted in long-established traditions in critical sociological research (Gilmore et al., 2019), I present extensive excerpts in the next section to centre Ashley's voice and vividly illustrate the profound impact her injury and its management had on her health and wellbeing. 


\section{Ashley's Story}

\section{The Injury}

I'd never experienced pain like that before. It felt like I was being struck by lightning over and over again as the excruciating pain travelled through my entire spine every time I took a step. Cold sweat poured down my back. I eventually crawled my way over to my phone and called an ambulance. I wasn't doing anything unusual when it happened. My back felt slightly stiff when I woke up that morning but nothing out of the ordinary. I worked through the day at the office as the pain grew. When I got home, I took a shower, planning to turn in early for the night, but as I laid in bed, the pain intensified to a point I knew that something was very wrong. That scared me. The fact I couldn't attribute my injury to an accident or really anything in particular I had done. If it surprised me like that, I was afraid that it could happen again without warning.

The doctor at the emergency clinic suspected that Ashley suffered a disc injury. She was prescribed painkillers and muscle relaxants and given a referral for an MRI scan. The scan eventually revealed two bulging discs in her lower back. She began seeing a physiotherapist twice a week. This might be where a traditional OHS study might end, having measured a discreet incident of injury or illness, but this was only the beginning of Ashley's injury.

My manager was sympathetic over the phone when I informed him about my injury the next morning. I was bedridden and he approved me to take a week of sick leave, but both he and I expected that I would continue working. Even on a constant stream of strong painkillers, I couldn't sit in a chair for longer than half an hour without pain. I would repeatedly wake up through the night from the pain. I could only walk by shuffling very slowly across flat surfaces, but those lightning shocks of pain would come back every time I tried to climb stairs. I spent my entire leave working, on the phone multiple times a day coordinating with my manager and help find staff to take over my classes and then sending them my lecture slides and activity plans with non-stop back-and-forth instructional emails. Every request I received started with "Sorry to bother you while you're on sick leave, but...". Trying to use my laptop from bed while having to keep my back flat quickly led to an inflammation in my neck. It felt like my job was trying to kill me.

In order to minimise her pain while working from home, Ashley purchased a sit-stand desk on her physiotherapist's advice, which allowed her to alternate between sitting and standing every 20 min and cope with the pain that aggravated with immobility. This arrangement allowed her to progress her research and administrative duties from home, but Ashley remained concerned about her on-campus teaching. Her physiotherapist encouraged her to seek adjustments to her work duties so she could have more freedom over her pain relief.

My manager uttered sympathetic platitudes about my injury but seemed reluctant to consider or offer longerterm support. Since my injury, I had coordinated my own teaching relief while trying to manage writing deadlines, admin, and chasing up a health and safety coordinator from human resources who didn't return my emails or calls. The unspoken expectation that I'd just get over my injury and get on with my work felt like a growing impossibility with the intense and persistent pain.

I finally caught the health and safety coordinator on the phone four weeks after my injury. She was cheery and warm on the phone but had a habit of repeating my name in every sentence like a telemarketer. I relayed my physiotherapist's advice and she advised that any adjustments I needed with my work can be directly negotiated with my manager as long as they're supported by medical statements. I immediately emailed my physiotherapist after and asked him to put his advice in writing to say I should only do tasks during which I can freely sit, stand, and move about.

I battled between pain and guilt, and eventually, I asked my manager if I could be relieved from tutorials where I would have the least flexibility to move around or take breaks. I offered to continue taking my lectures even though privately, I worried about how I would climb the stairs to get to the theatre and feared being overwhelmed with pain in front of my students. I kept imagining my brokenness exposed to students if I collapsed on the floor of the theatre, screaming and crying from pain as I did in my bedroom waiting for the ambulance.

My manager agreed to accommodate my request.

\section{The Denial}

A week later the day before my classes, the health and safety coordinator called me to say that she wouldn't approve the agreement I made with my manager after all. She explained that the university can't make accommodations on the advice of a physiotherapist and they needed a letter from a doctor instead to answer a series of questions about my diagnosis, prognosis, and workplace adjustment 
requirements, with a summary statement concluding "whether you are fit to perform the inherent requirement of your role".

I was irritated that these instructions hadn't been specified at our first call. She had said nothing about a doctor let alone the template of questions. But I also began questioning myself. The disconnect between our two conversations were so stark. I wondered if my pain was affecting my interpretations or my memories of conversations with the health and safety coordinator. Maybe she did send me these questions, but I forgot? Maybe I got confused and accidentally told her I'll get her a letter from my GP?

My manager was amused. When debriefing about this sudden change in plans, he shares how the health and safety coordinator calls him after every phone call with me to verify my claims. He imitates her furtive questioning, whispering "is Ashley really allowed to be working from home?" and laughs at her ignorance about academic work. Meanwhile, students are emailing me every day asking what is happening with our classes every time I bear the pangs of guilt to say, "I don't know". My chronic pain became constant and unbearable, exacerbated by the uncertainty and stress of the situation.

When I returned to my GP with the set of questions from the health and safety coordinator, she was unimpressed. She asked me to describe all my work tasks and concluded in her letter that I ought to "participate only in work that allows regular sit/stand breaks as required based on her symptoms and has capacity to work in aspects of her current role that does not involve teaching". I dreaded telling my manager the news. As I was leaving her office, she asked me point blank, "Are you sure I can't be filling out a workers compensation report for you?". Her question stumped me. I went home and reviewed the OHS flowchart. It specified that it is the employer's responsibility to lodge a notice with the insurer within 48 hours of a worker reporting their injury. I assumed then my case must be ineligible, but the question nagged at me.

The health and safety coordinator called me immediately after she received the medical certificate, her friendly demeanour is strained, her suspicion and impatience barely concealed. "But why would the doctor say you can't teach?"

"I gave her your questions and that is her professional recommendation".

"So, if you can't teach, what are you supposed to do?" I began telling her about my research, the book I was working on, a grant I received, the service roles I still fulfilled. It was like I could hear her eyes glaze over through the line.
She concludes with an ultimatum. "From the university's perspective, either you're fit for all your work duties or you are not. If you can't teach, it's better if you just take extended sick leave".

That conversation led Ashley to begin seriously doubting the process with human resources. The OHS policy she read clearly showed that all injuries would be accommodated wherever possible. She reached out to two senior colleagues for their opinions. A professor at her institution she trusted confirmed that the health and safety coordinator was correct. Another professor at a different university complained to Ashley, "I had to take over a subject last year from a colleague who had an accident. It was such a pain".

I wondered if my colleagues also thought I was a pain.

Ashley nevertheless confronted the health and safety coordinator and asked why her doctor was made to specify the diagnosis, prognosis, and workplace adjustment requirements if the only options were to complete her duties in full without adjustments or to take sick leave.

With a sneer, the health and safety coordinator reminded me of my initial offer. "Why would your doctor say you can't cope with teaching if you told us you would deliver lectures?" She continued to muse aloud, "I was also thinking you should be able to deliver your tutorials as well if you just roll out a yoga mat in the back of the classroom and do some stretches when your pain flares up".

My anxious overachievement that brought about my back injury in the first place was used against me. I had become an unreliable witness to my own pain. I was branded a liar.

Ashley called the advice line of the state insurance regulatory department the next day. The advisor she spoke to confirmed that her injury qualifies as a work-related injury and that she should file a workers compensation certificate with her doctor immediately.

I quoted the health and safety coordinator's directive that I take extended sick leave if I can't do all my duties.

The line is silent for a moment.

When the advisor speaks, it is soft, slow, and clear. "That's against the law".

\section{The Recovery}

The insurer accepted liability of my workers compensation claim outright. I receive a form letter from the human resources office stating that they will comply with regulation and policy to make reasonable adjustments to my work with no mention of their previous 
ultimatum. The follow-up meeting is a theatrical display of ethics. The coordinator effuses sympathetic platitudes as though she's just heard of my injury for the first time. She rattles off directives like how I should squat down to pick up anything I drop on the floor and not be shy to ask colleagues to help me carry heavy objects around the office, her advice contradicting the regiment of regular movement and exercise that my physiotherapist recommended.

"My university tried to trick me out of workers compensation", plays over and over in my mind as resentment twists and knots in my stomach.

"Why didn't you report my injury to the insurer as your policy says you would?" I asked her point blank. "We, uh, well rely on, line managers, to report."

"Why didn't you advise me or my manager that I may be eligible for workers compensation?"

"I really wasn't deliberately keeping that from you! If you had asked me if you were eligible, I would've said yes."

I' $m$ in near constant pain. The insurer sends a rehabilitation officer to devise a return-to-work assessment. She doesn't stop writing from the moment she shakes my hand to when she leaves my office. She gets me to describe in tedious detail everything I do for my work down to the minutes I sit, stand, and walk. She asks me things like how frequently I reload the photocopier and how heavy the stack of papers would be. She takes photographs of me working at the computer, reading, and writing notes. Every action, even "prolonged grasp and in hand manipulation of pen", is added to her notes. The profusion of scientific language pads the 8-page report, which recommends that I should only be doing "non-teaching duties 7 hours per day $\mathrm{x}$ 5 days per week".

Increased research performance expectations in universities over the last few decades have led to escalating workloads for staff (Kinman, 2001). Like 90 per cent of other full-time Australian academics, Ashley worked well over $40 \mathrm{~h}$ a week prior to her injury (Strachan et al., 2012, p. 35). What led the insurer to accept liability were the reports from Ashley's medical specialists who attributed long sedentary working hours to her injury. In the weeks leading up to her injury, Ashley was working 12-h days writing a conference paper, finalising a book, submitting travel reimbursement claims, teaching three subjects, marking assignments, and investigating student plagiarism cases. Much of this work was invisible as human resources could not understand what an academic did with their time outside classes. They treated her accounts of work tasks with suspicion.

My manager, who had initially been sympathetic and supportive, became more withdrawn over time.
I sought a meeting with him to clear the air and he confessed he was "taken aback" at my workers compensation claim as though he was the victim in the situation. I relayed how the health and safety coordinator suggested he should've been the one to lodge a claim with the insurer. He leaned back in his chair for a moment and recalled aloud, "I guess the only time I can remember a workers compensation case in the department is when David had a load of boxes fall on his head a few years ago and he just knew the workers compensation process well enough to file the certificate himself."

He also admitted the coordinator had checked in recently with him, again, to verify my claims that I was expected to work beyond my formal full-time workload of 35 hours a week. He told her that he "couldn't think of any reasons why" I'd be working so much since it was the end of semester. Despite her contrite displays at our last meeting, I guess I was still the lying employee who couldn't be trusted. I drew up a table showing all my current work tasks and the 53 hours I was spending on them each week for both my manager and the health and safety coordinator. "Looks good", my manager quipped, missing the point entirely. "Maybe cut back on the journal editing?" (a mere $4 \mathrm{~h} /$ week allocation in my table).

I was working more days from home but my manager, my primary contact within the department, stopped communicating with me. Even days I came into the office, he struggled to look me in the eye. Given how casually he disclosed my colleague's injury to me, I wondered to how many of my colleagues he had griped about my injury. Around that time, my physiotherapist told me that there were no physiological reasons why my back muscles would continue to be inflamed three months after my injury except that my stress at work was impeding my physical recovery. My GP wrote me a referral for a psychologist. She stated on my medical certificate that "ongoing workplace resistance and obstructiveness impacted psychosocial rehabilitation". My mother gently suggested if I could just resign from my job and focus on my health. I replied that I wished I had just died instead.

\section{Injury and Illness in Academic Bodies}

Ashley's account of her experience with a back injury lays bare the harm enacted on academic bodies in the neoliberal university (Clarke \& Knights, 2015; De Vita \& Case, 2016; Jones et al., 2020; Keashly \& Neuman, 2014; Smith \& Ulus, 2020) and the institution's neglect of their duty of care in dysfunctional and distrustful OHS processes. Her 
narrative highlights the inseparability between physiological and psychosocial injury where her chronic pain triggered her mental anguish and the resultant stress further aggravated her physical pain. The mutually constitutive pain and stress Ashley endured were produced and exacerbated within a wider academic culture of self-disciplining individualism, performativity, and overwork (Connell, 2014) that impeded the ethical policies and practices of her organisation.

Specifically, Ashley's case suggests how academic bodies are expected to be invisible and unfailing (Brown, 2020). The disembodied nature of the masculinist academe perpetuates the assumption that academics are minds before they are bodies. As such, as long as academics are conscious, they can and should work; overcoming any physical limitations through self-governance with indiscernible disruptions to their productivity (Ruth et al., 2018). These expectations of academic productivity are entwined with an individualist logic (Ratle et al., 2020). Ashley's account suggests a persistent assumption from others, and herself, that she ought to get over any disturbances to her work and get on with her work tasks. Ashley unquestioningly accepted personal responsibility for addressing and circumventing the physical restrictions of her 'failed', injured body (Fan et al., 2019; Frick, 2011; Gifford \& Holmes, 1996; Hart, 2010), such as when she purchased a sit-stand desk at her own expense immediately after her injury so that she could continue to coordinate teaching relief and answer emails from home, even during her sick leave. Ashley was complicit with this disciplinary regime in initially offering to continue delivering lectures even though she knew she could not cope with sustaining a task for two hours without breaks. Her self-disciplining tendency was then used against her to cast doubt on the doctor's assessment that she was unfit for teaching and the rehabilitation manager's recommendation that Ashley only work $35 \mathrm{~h} /$ week during her recovery.

The management of academic bodies suggests a lack of bodily integrity (Earp, 2015; Garland-Thomson, 2017; Svenaeus, 2014). Ashley struggled to define her own pain at work. She felt her pain was repeatedly denied and trivialised by the human resources staff who without understanding the details of her injury, speculated how it could and should be relieved through dangerous lay ergonomics advice and asinine solutions like pausing her classes to do some yoga in the back of a classroom.

The individualist logic of OHS in academia extended to Ashley's navigation of regulation and policy (Zoller, 2003). Although her institution's policy stipulated a clear standard operational procedure in which the human resources department would report work-related injuries to the workers compensation insurer within $48 \mathrm{~h}$ of the accident, the health and safety coordinator who handled Ashley's case evaded this responsibility. This initially led Ashley to believe that she was ineligible for workers compensation and deterred her from pursuing a claim. When by chance she received information about workers compensation from her doctor, Ashley sought advice from the state regulatory authority and lodged a certificate outside her institution. She remarked that if it was not for her doctor's comment, she would have exhausted her sick leave and expended thousands of dollars out of pocket for physiotherapy treatments, counselling, and medication.

When Ashley confronted her university about this breakdown in the OHS procedure, the health and safety coordinator implied that had she only explicitly asked about workers compensation, the university would have filed an insurance claim. Her manager could only remark that the OHS procedure was followed in the past when a previous injured academic took full responsibility for the insurance claims process. Both parties seemed indifferent to their neglect of institutional policy and procedure and contraventions of the legal requirements around workplace adjustments.

The lack of an informed third-party who could intervene in Ashley's workplace meant she, and likely other workers, felt isolated when the injury occurred. Ashley was dependent on her employer for complying with legal requirements and institutional policy and was vulnerable to the power asymmetry when human resources staff misrepresented her rights and their responsibilities. Although Ashley contacted the union for advice after the health and safety coordinator contradicted her initial claim that any arrangements can and should be negotiated directly with her manager, Ashley was told that the industrial officer was overloaded with cases across two campuses. She waited eight days for a brief e-mail from the industrial officer confirming she should file a workers compensation certificate. The culture of overwork that pervaded academia was equally reflected in the underresourced branches of Ashley's union who were ultimately unable to provide advocacy.

Previous research has similarly revealed under-resourced and overworked OHS inspectorates that lead to the low prosecution of legal breaches (MacEachen et al., 2016). The inadequate enforcement of the law has led some critics to observe the effective decriminalisation of OHS statutes, particularly in Australia and the UK, leading to little incentive on the part of employers to prevent future injuries (Matthews et al., 2019). Ashley's case raises questions about the dwindling mechanisms of support available to staff and the everwidening power asymmetry between workers and employers (MacEachen et al., 2016).

The seeming incompetence of the health and safety coordinator who handled Ashley's injury remains one of the most striking aspects of her case. The actions of human resources appeared to be guided by an ingrained distrust of staff, with Ashley treated from her initial report as someone fabricating their pain in order to shirk their work duties. The fear of suspicion leads many disabled academics to choose to hide their 
disabilities, where possible, from their employers (Brown, 2020). Institutionalised distrust has eroded previous understandings that university staff could be relied on to do their jobs within professional and collegial communities (Connell, 2014; Kinman, 2001). The surreptitious checks the health and safety coordinator made with Ashley's manager to verify her claims revealed the pervasive mechanisms of surveillance within the neoliberal university (Connell, 2014). In contrast to their traditional obligations to worker welfare, the health and safety coordinator seemed to see her role as a corporate defender, protecting the business from lazy and duplicitous staff.

Academic culture promotes the assumption that individual employees should self-manage their illnesses and injuries. Not only is it presumed that they will somehow minimise their own musculoskeletal and psychosocial injury risks in an environment where 50- $\mathrm{h}+$ working weeks are normalised (Kinman, 2001; Morrish, 2019), but Ashley's case suggests that individual employees are also expected to interpret policy and regulation and take responsibility for reporting (Frick, 2011; Gifford \& Holmes, 1996; Hart, 2010). Within these expectations, universities and their human resource departments can partially evade their legal obligations and duty of care. Organisational ethics thus broke down in the division between policy and practice. The policies outlined the employers' OHS responsibilities, yet academic norms and practices compelled academics to become self-governing subjects who take personal responsibility to overcome any barriers to their never-ending production of capital for the institution (Brown, 2020). Ashley's university and its human resources department were in a sense spared from legal, policy, and ethical comprehension/ compliance within the self-disciplining order that shapes academic subjectivities.

Guilt, in particular, was a recurring feature in Ashley's account and a mechanism of social control in the neoliberal university (Ratle et al., 2020). Her manager and multiple senior colleagues perpetuated the assumptions that illness and injury ought to be borne by the individual academic and that when they could not endure their conditions without disruption, they were told they would cause 'pain' to their colleagues who needed to cover their research, teaching, or administrative tasks. Being in pain was equivalent to being a pain. As such, Ashley's experience shows that job blackmail (Zoller, 2009) need not be an overt and deliberate act on the part of employers but can be a subtle and pernicious aspect of academic culture. In academia, the dualism between jobs versus health (Zoller, 2009) is invoked when universities marginalise unhealthy and 'failing' bodies (Peruzzo, 2020). Academics are then pitted against one another with employers relying on relational bonds and responsibilities between colleagues to encourage self- and peer-regulation of productivity. When responsibilities of sick and injured academics are thrusted onto their colleagues, workers like Ashley may feel that they are harming their colleagues when they require OHS support. Ashley's teaching activities were eventually taken up by casual staff rather than delegated to full-time colleagues as unpaid overtime. Yet the threat that colleagues would be shouldering 'her' burden was enough to make Ashley feel as though she was letting her department down, even when her condition was caused by her excessive workload in the first instance.

Existing research of work-related stress in universities tend to focus on escalating research performance expectations and metrics as the primary source (Jones et al., 2020; Winefield et al., 2008). In Ashley's case, her institution expressed no explicit interest of or concern for how her injury impacted her research. In some ways, this was due to the unquestioned academic assumption that research can and should progress irrespective of illness and injury. This assumption is so ingrained that for Ashley, suspending her research projects, failing to deliver on her book, withdrawing journal articles, or relying on her co-authors to take over writing were inconceivable. For her manager and human resources, research and administrative activities were nonnegotiable, and therefore invisible.

Ashley's university was more concerned with the visible work of teaching. For the health and safety coordinator, teaching was the only task she understood academics to perform. Her naïve incredulity that Ashley would have work outside teaching or could be 'permitted' by her manager to work from home reflected this narrow view of what constitutes academic work. Teaching mattered because it was the only part of Ashley's work that could be delegated to someone else, unlike her research. It was also the area of Ashley's workload that was least flexible. She would not be able to control when and for how long she taught or her accessibility in climbing stairs and taking breaks during classes.

A concerning underlying element in Ashley's story is the distrust and contempt she was shown as an injured employee (Connell, 2014). Smith and Ulus (2020) recognise that the neoliberal structures of the university are in many ways antithetical to caring yet nevertheless calling for an answer to the question: 'who cares for academics?' Ashley's case suggests that care would unlikely come from the employer despite their formal duty of care to their workers. Ashley's university doubted her accounts of her injury and disability as well as her work tasks and workload from the outset without basis, even when it contradicted the medical opinion of healthcare professionals. Her care came instead from everywhere else - her doctor, her physiotherapist, her psychologist, the rehabilitation manager, the state regulatory authority, even the insurer, and countless colleagues who offered to deliver supplies and share wisdom from their own injuries. Along with family and friends, this extensive 
network of care was necessary to see Ashley through her recovery within this brutal environment.

\section{Summary and Conclusions}

\section{Summary of Findings}

With work-related injuries and illnesses on the rise globally, OHS theorising, policies, and practices need to adapt to the changing nature of contemporary work (Fan et al., 2019; Hämäläinen et al., 2017; Takala et al., 2014). As critical examinations have shown, neoliberal ideology has sought to transfer cause and responsibility of injuries and illnesses onto individual workers (Hart, 2010; Zoller, 2003, 2009) while marginalising disabled bodies (Brown, 2020; Newell, 2006; Peruzzo, 2020). This still somewhat peripheral strand of OHS research offers inroads to a richer understanding of escalating work-related stress and other mental health issues in academia within the wider sociopolitical landscape of the academy (Morrish, 2019; Pignata et al., 2018; Ratle et al., 2020; Smith \& Ulus, 2020; Winefield et al., 2008).

This article adopted a critical constructionist analysis of the OHS processes experienced by an injured academic who attempted to navigate her recovery amidst the complex, messy assumptions around risk, health and safety, and the academic body. In answering the research question: (1) How is an incident of workplace injury constructed between the injured worker, their employer, and other social actors through the OHS process? The study suggested that an individualist logic dominated how Ashley and her employer perceived and managed her injury.

Specifically, both Ashley and her manager assumed that she would self-manage her injury and wilfully overcome the physical limitations to her productivity. Ashley purchased office equipment and worked from home through her sick leave in order to maintain an idealised identity as a high-achieving, performative academic. When selfmanagement proved insufficient for the severity of ongoing symptoms and the worker sought institutional support, she became increasingly problematised by her employer. Initial suspicion turned into what appeared to be distrust and even contempt. The breakdown of trust happened both ways when Ashley discovered that human resources circumvented their ethical and legal responsibilities of OHS management, leading to the deterioration of her psychosocial health while exacerbating her chronic physical pain.

In answering the second question: (2) In what ways does power inform the construction of work-related injury and its recovery? Ashley's experience suggested that her employer was able to rely on the wider academic cultures of performativity and overwork. The dominant norms and practices in this context enable employers to leverage a more subtle and diffuse form of job blackmail (Zoller, 2009), where they are able to rely on the self-disciplining regime in academia to see individual employees take over responsibility for overcoming bodily limitations, navigating regulatory frameworks, and managing their own recoveries with minimal impact on university operations. This study of an injured academic shows how the ideological, regulatory, managerial, organisational, and relational dimensions of OHS are important because examined together, they allow researchers to develop more holistic understandings of how workplace safety and hazards are socially and politically constructed in organisations.

\section{Research Limitations and Future Research}

At this article's writing, we are attempting to survive in the midst of a global pandemic. COVID-19 has produced new implications for illness and how illness is coped with and cared for in universities. Just as I began writing this article in September 2020, I heard the news of Paola De Simone, a professor at the Universidad Argentina de la Empresa who collapsed while teaching a class over Zoom after having been sick with COVID-19 for four weeks. Her university remembered her as a "passionate and dedicated teacher". Many of us would likely relate to the expectations to work at all costs, pushing through teaching and research duties despite being sick or in pain, or risk earning distrust and disdain from our employers and colleagues if we sought too many accommodations (Brown \& Leigh, 2020).

Focussing here on the case of a single injured worker, there are limitations to the study that may be addressed in future research. Ashley's account centred on her own experiences of her injury and her struggles constructing how the injury impacted her body and her productivity with her employer. Given Ashley's account of ethical malpractice on the part of her employer, it did not seem advisable in this sensitive case to pursue interviews with the employer and expose Ashley as a whistleblower. As such, the study can only be considered to provide insight into an injured worker's experience and perception of care (and its lack thereof) in the individualising OHS systems of a neoliberal university, and the effects on her physical and psychosocial health. Future research has the potential to examine the discursive co-construction of injury through interviews with multiple actors in the OHS system and their collective struggles over meaning.

Additionally, focussing on Ashley's account could not generate insights into the role of and effects on witnesses to her injury. In other words, by interviewing one actor and their perspective of the events, this study does not explore how some of her colleagues' potential vicarious exposure to the injury and its management likely affected their 
perceptions of the university (Barling et al., 2003). Future research could usefully seek accounts from witnesses and bystanders to complement the rich qualitative accounts from injured workers about how observing the ways fellow academics are cared for (or not cared for as it may be the case; Smith \& Ulus, 2020) inform their senses of safety and trust in their organisation (Barling et al., 2003).

In reviewing the relevant literatures around workplace injury, I found somewhat isolated research conducted within the fields of OHS, critical management studies, and critical disability studies. This was especially problematic in OHS studies that reproduced neoliberal values of individualism and performativity while ignoring the oppressive systems of power in organisations and society (for exceptions, see Frick, 2011; Hart, 2010; Ståhl et al., 2014; Zoller, 2003, 2009). Critical management studies tended to focus on broad critiques of power but rarely grounded such critiques in analyses of mundane structures and mechanisms such as OHS policies and procedures. Future research could work to bridge the divide between these two fields and generate richer analyses of the OHS issues exacerbated along with deteriorating work conditions in the academy and beyond.

Critical disability studies, in many ways, provide promising analyses of how neoliberal, patriarchal, and ableist ideologies can be sustained or subverted through OHS policies and procedures. Critical disability studies' intervention in bioethics has challenged mainstream medical thinking and practice (Brown, 2020; Newell, 2006; Peruzzo, 2020). Similarly, organisational ethics theorising and practice need to centre the testimonies of injured, ill, and impaired workers, and use their lived experiences as the starting point for designing policies and procedures (Brown \& Leigh, 2020).

This article has contributed to growing calls for critical examination of health and wellbeing in the academy, amidst wider pressures for marketisation. The COVID-19 pandemic has also prompted many universities around the world in the face of declining student enrolments to foreshadow imminent austerity measures. In this neoliberal climate, the violences of academic culture-and our suffering as university staff-may become more acute.

Ultimately, changes to policy and practice would be limited without collective and sustained resistance against the prevailing ideologies that have enabled the experiences of Ashley and countless other workers. Within increasingly corporatised universities, there is unlikely to be adequate impetus for change unless internal pressures are matched with external pressures from staff, unions, students, and the public. Collective refusal to support cultures of individualism, performativity, and overwork may align with growing stakeholder expectations that universities maintain workplaces that are inclusive of differently abled bodies. The intersection of these conditions will likely be necessary for meaningful change to OHS practices in academia.
Smith and Ulus (2020) ended their article after detailing the raw disclosures of academics with the questions: "But who is listening? And, who cares?".

We are all listening to one another.

We listen while working 12-h workdays. We listen while working through sick leave. We listen while on pain relief. We listen while awake in the middle of the night unable to sleep. We listen while having a panic attack. We listen from our doctor's office and our therapist's office and our physiotherapist's office.

And I hope that we can listen to the pain and suffering of our more precarious, junior, and administrative colleagues in the neoliberal university who do not have access to these scholarly platforms to speak. Who are under even greater pressures to keep silent about their suffering and 'get on' with exploitative workloads.

Through our listening, we can recognise the unrealistic, untenable, and unethical demands of the academy and their ongoing assaults on our bodies, minds, and spirits. We must stand together against these academic norms so that we can all be well again.

\section{Declarations}

Conflict of interest The author, Helena Liu, declares that she has no conflict of interest.

\section{References}

Barling, J., Kelloway, E. K., \& Iverson, R. D. (2003). Accidental outcomes: Attitudinal consequences of workplace injuries. Journal of Occupational Health Psychology, 8(1), 74-85.

Berg, M., \& Seeber, B. K. (2016). The slow professor: Challenging the culture of speed in the academy. University of Toronto Press.

Berger, P. L., \& Luckmann, T. (1966). The social construction of reality: A treatise in the sociology of knowledge. Doubleday.

Bone, K. D. (2020). Cruel optimism and precarious employment: The crisis ordinariness of academic work. Journal of Business Ethics. https://doi.org/10.1007/s10551-020-04605-2

Brown, N. (2020). Introduction: Theorising ableism in academia. In N. Brown \& J. Leigh (Eds.), Ableism in Academia (pp. 1-10). UCL Press.

Brown, N., \& Leigh, J. (Eds.). (2020). Ableism in academia. UCL Press.

Burr, V. (2003). Social constructionism (2nd ed.). Taylor \& Francis.

Castle, P. F. C. (1956). Accidents, absence, and withdrawal from the work situation. Human Relations, 9(2), 223-233.

Clarke, C. A., \& Knights, D. (2015). Careering through academia: Securing identities or engaging ethical subjectivities? Human Relations, 68(12), 1865-1888.

Connell, R. W. (2014). Love, fear and learning in the market university. Australian Universities' Review, 56(2), 56-63.

De Vita, G., \& Case, P. (2016). 'The smell of the place': Managerialist culture in contemporary UK business schools. Culture and Organization, 22(4), 348-364. 
Earp, B. D. (2015). Female genital mutilation and male circumcision: Toward an autonomy-based ethical framework. Medicolegal and Bioethics, 5, 89-104.

Fan, D., Zhu, C. J., Timming, A. R., Su, Y., Huang, X., \& Lu, Y. (2019). Using the past to map out the future of occupational health and safety research: Where do we go from here? International Journal of Human Resource Management, 31(1), 90-127.

Frick, K. (2011). Worker influence on voluntary OHS management systems: A review of its ends and means. Safety Science, 49(7), 974-987.

Garland-Thomson, R. (2017). Disability bioethics: From theory to practice. Kennedy Institute of Ethics Journal, 27(2), 323-339.

Gifford, S., \& Holmes, N. (1996). Social meanings of risk in OHS: Consequences for risk control. Journal of Occupational Health and Safety, Australia and New Zealand, 12(4), 443-450.

Gilmore, S., Harding, N., Helin, J., \& Pullen, A. (2019). Writing differently. Management Learning, 50(1), 3-10.

Giroux, H. A. (2014). The swindle of democracy in the neoliberal university and the responsibility of intellectuals. Democratic Theory, 1(1), 9-37.

Hämäläinen, P., Takala, J., \& Kiat, T. B. (2017). Global estimates of occupational accidents and work-related illnesses 2017 (pp. 1-21). Workplace Safety and Health Institute. Retrieved 1 Sept 2020, from https://www.wshi.gov.sg/-/media/wshi/past-publi cations/2017/global-estimate-of-occupational-injuries-and-workr elated-illnesses-2017.pdf.

Hart, S. M. (2010). Self-regulation, corporate social responsibility, and the business case: Do they work in achieving workplace equality and safety? Journal of Business Ethics, 92(4), 585-600.

Hart, S. M. (2013). The crash of Cougar Flight 491: A case study of offshore safety and corporate social responsibility. Journal of Business Ethics, 113(3), 519-541.

Hossain, M. A., Hossain, Md. M., Tarannum, S., \& Chowdhury, T. H. (2015). Factors affecting OHS practices in private universities: An empirical study from Bangladesh. Safety Science, 72, 371-378.

Jones, D. R., Visser, M., Stokes, P., Örtenblad, A., Deem, R., Rodgers, P., \& Tarba, S. Y. (2020). The Performative University: 'Targets', 'terror' and 'taking back freedom' in academia. Management Learning, 51(4), 363-377.

Kazis, R., \& Grossman, R. (1991[1988]). Fear at work: Job blackmail, labor and the environment. Pilgrim Press.

Keashly, L., \& Neuman, J. H. (2014). Faculty experiences with bullying in higher education: Causes, consequences, and management. Administrative Theory \& Praxis, 32(1), 48-70.

Kinman, G. (2001). Pressure points: A review of research on stressors and strains in UK academics. Educational Psychology, 21(4), 473-492.

Laberge, M., \& Ledoux, E. (2011). Occupational health and safety issues affecting young workers: A literature review. Work, 39(3), 215-232.

Maceachen, E., Kosny, A., Ståhl, C., O’Hagan, F., Redgrift, L., Sanford, S., Carrasco, C., Tompa, E., \& Mahood, Q. (2016). Systematic review of qualitative literature on occupational health and safety legislation and regulatory enforcement planning and implementation. Scandinavian Journal of Work, Environment \& Health, 42(1), 3-16.

Manathunga, C., \& Bottrell, D. (Eds.). (2019). Resisting neoliberalism in higher education volume II: Prising open the cracks. Springer.

Matthews, L. R., Johnstone, R., Quinlan, M., Rawlings-Way, O., \& Bohle, P. (2019). Work fatalities, bereaved families and the enforcement of OHS legislation. Journal of Industrial Relations, 61(5), 637-656.

Miller, P., \& Rose, N. (1988). The Tavistock programme: The government of subjectivity and social life. Sociology, 22(2), 171-192.

Morrish, L. (2019). Pressure vessels: The epidemic of poor mental health among higher education staff (No. HEPI Occasional Paper
20) (pp. 1-75). Higher Education Policy Institute. Retrieved 3 Sept 2020, from https://www.hepi.ac.uk/wp-content/uploads/ 2019/05/HEPI-Pressure-Vessels-Occasional-Paper-20.pdf.

Neal, A., Griffin, M. A., \& Hart, P. M. (2000). The impact of organizational climate on safety climate and individual behavior. Safety Science, 34(1-3), 99-109.

Newell, C. (2006). Disability, bioethics, and rejected knowledge. Journal of Medicine and Philosophy, 31(3), 269-283.

Oketunji, S. F. (2014). Influence of occupational health and safety (OHS) information availability and use on job performance of library personnel in public universities in South-West Nigeria. European Scientific Journal, 10(14), 337-350.

Parboteeah, K. P., \& Kapp, E. A. (2008). Ethical climates and workplace safety behaviors: An empirical investigation. Journal of Business Ethics, 80(3), 515-529.

Peruzzo, F. (2020). I am not disabled: Difference, ethics, critique and refusal of neoliberal academic selves. In N. Brown \& J. Leigh (Eds.), Ableism in academia (pp. 31-50). UCL Press.

Pignata, S., Winefield, A. H., Boyd, C. M., \& Provis, C. (2018). A qualitative study of HR/OHS stress interventions in Australian universities. International Journal of Environmental Research on Public Health, 15(1), 103-118.

Ratle, O., Robinson, S., Bristow, A., \& Kerr, R. (2020). Mechanisms of micro-terror? Early career CMS academics' experiences of 'targets and terror' in contemporary business schools. Management Learning, 51(4), 452-471.

Richardson, K. M., \& Rothstein, H. R. (2008). Effects of occupational stress management intervention programs: A meta-analysis. Journal of Occupational Health Psychology, 31(1), 69-93.

Ruth, D., Wilson, S., Alakavuklar, O., \& Dickson, A. (2018). Anxious academics: Talking back to the audit culture through collegial, critical and creative autoethnography. Culture and Organization, 24(2), 154-170.

Saari, J. (1995). Risk assessment and risk evaluation and the training of OHS professionals. Safety Science, 20(2-3), 183-189.

Shaw, W. S., Robertson, M. M., Pransky, G., \& McLellan, R. K. (2003). Employee perspectives on the role of supervisors to prevent workplace disability after injuries. Journal of Occupational Rehabilitation, 13(3), 129-142.

Smith, C., \& Ulus, E. (2020). Who cares for academics? We need to talk about emotional well-being including what we avoid and intellectualize through macro-discourses. Organization, 27(6), 840-857.

Ståhl, C., MacEachen, E., \& Lippel, K. (2014). Ethical perspectives in work disability prevention and return to work: Toward a common vocabulary for analyzing stakeholders' actions and interactions. Journal of Business Ethics, 120, 237-250.

Strachan, G., Troup, C., Peetz, D., Whitehouse, G., Broadbent, K., \& Bailey, J. (2012). Work \& careers in Australian Universities: Report on employee survey (pp. 1-83). Centre for Work, Organisation and Wellbeing. Retrieved 10 Sept 2020, from https:// www.griffith.edu.au/_data/assets/pdf_file/0024/88125/Workand-Career-Report-on-Employee-Survey_Final-v2.pdf.

Svenaeus, F. (2014). The phenomenology of suffering in medicine and bioethics. Theoretical Medicine and Bioethics, 35(6), 407-420.

Takala, J., Hämäläinen, P., Saarela, K. L., Yun, L. Y., Manickam, K., Jin, T. W., Heng, P., Tjong, C., Kheng, L.G., Lim, S., \& Lin, G. S. (2014). Global estimates of the burden of injury and illness at work in 2012. Journal of Occupational and Environmental Hygiene, 11(5), 326-337.

Tucker, S., Ogunfowora, B., \& Ehr, D. (2016). Safety in the c-suite: How chief executive officers influence organizational safety climate and employee injuries. Journal of Applied Psychology, 101(9), 1228-1239. 
Turner, N., \& Tennant, S. J. (2010). "As far as is reasonably practicable": Socially constructing risk, safety, and accidents in military operations. Journal of Business Ethics, 91, 21-33.

Utoft, E. H. (2020). 'All the single ladies' as the ideal academic during times of COVID-19? Gender, Work and Organization, 27(5), $778-787$.

Watts, J., \& Robertson, N. (2011). Burnout in university teaching staff: A systematic literature review. Journal Educational Research, 53(1), 33-50.

Winefield, T., Boyd, C., Saebel, J., \& Pignata, S. (2008). Update on national university stress study. Australian Universities Review, 50(1), 20-29.

Zohar, D. (1980). Safety climate in industrial organizations: Theoretical and applied implications. Journal of Applied Psychology, 65(1), 96-102.
Zoller, H. M. (2003). Health on the line: Identity and disciplinary control in employee occupational health and safety discourse. Journal of Applied Communication Research, 31(2), 118-139.

Zoller, H. M. (2009). The social construction of occupational health and safety: Barriers to environmental-labor health coalitions. New Solutions, 19(3), 289-314.

Publisher's Note Springer Nature remains neutral with regard to jurisdictional claims in published maps and institutional affiliations. 